\title{
Carcinoma renal de células cromófobas, una entidad excepcional en la infancia: caso clínico
}

\author{
Fernández Pineda I, Cabello Laureano R, Maraví Petri A, Carranza Carranza A*, \\ Congregado Córdoba J*, De Agustín Asensio JC. \\ Servicio de Cirugía Pediátrica. Servicio de Anatomía Patológica*. \\ Hospital Universitario Virgen del Rocío. Sevilla. \\ Actas Urol Esp. 2008;32(6):662-665
}

\section{RESUMEN}

CARCINOMA RENAL DE CÉLULAS CROMÓFOBAS, UNA ENTIDAD

EXCEPCIONAL EN LA INFANCIA: CASO CLÍNICO

El carcinoma renal de células cromófobas (CRCC) es una variante rara de carcinoma renal que se origina de las células intercaladas del epitelio tubular distal y constituye un $5 \%$ de los tumores renales. Es un tumor de comportamiento biológico variable, menos agresivo que el carcinoma convencional de células claras. Presenta características histoquímicas, ultraestructurales y genéticas diferentes al resto de carcinomas renales. La edad de presentación suele ser hacia la $6^{\mathrm{a}}$ década de vida. Presentamos un caso excepcional de CRCC en un niño de 10 años de edad. Se revisan los aspectos diagnósticos y terapéuticos del manejo de este tumor.

Palabras clave: Carcinoma renal de células cromófobas. Oncocitoma renal. Nefrectomía.

\section{ABSTRACT \\ CHROMOPHOBE RENAL CELL CARCINOMA, AN EXCEPTIONAL ENTITY IN CHILDHOOD: A CASE REPORT}

Chromophobe renal cell carcinoma (CRCC) is a rare variant of renal carcinomas arising from the intercalated cells of the distal renal tubule and representing $5 \%$ among all renal tumors. Its biological behaviour is variable, less aggresive than clear cell renal carcinoma. Histochemical, ultrastructural and molecular genetic characteristics are different from other renal carcinomas. Age at presentation is about the $6^{\text {th }}$ decade of life. We report an exceptional 10 year-old boy case with a CRCC. Diagnostic and therapeutic aspects for the management of this tumor are reviewed.

Keywords: Chromophobe renal cell carcinoma. Renal oncocytoma. Nephrectomy.

$\mathrm{E}$ carcinoma renal de células cromófobas es un tumor derivado de las células del túbulo renal distal y supone un subtipo de carcinoma renal asociado con un pronóstico favorable. Representa aproximadamente el $5 \%$ de las masas renales primarias. Se presenta de manera unilateral en la mayoría de los casos. El diagnóstico diferencial con el oncocitoma renal es, en ocasiones, un reto para el patólogo. La presentación en la edad pediátrica es excepcional, siendo nuestro paciente uno de los más jóvenes publicados. Se trata de un niño de 10 años con diagnóstico ecográfico de masa renal y PAAF (punción- aspiración con aguja fina) compatible con oncocitoma renal (OR), cuyo resultado anatomopatológico definitivo fue de carcinoma renal de células cromófobas.

\section{CASO CLÍNICO}

Paciente de 10 años con antecedentes personales de epilepsia parcial compleja en tratamiento con valproato y dolor abdominal ocasional en los dos últimos años, que fue remitido a nuestro centro tras evidenciarse en un estudio ecográfico, realizado por molestias abdominales inespecíficas, una masa infrarrenal derecha de $5 \times 5 \mathrm{~cm}$. En la exploración física, no 
encontramos ningún hallazgo patológico significativo. En la RMN abdominopélvica se confirmaron los hallazgos de la ecografía previa, observándose una masa dependiente del polo renal inferior derecho de $5 \times 5 \times 4 \mathrm{~cm}$, de aspecto sólido con captación de contraste en la fase arterial. En el estudio no se evidenciaron adenopatías regionales. El juicio diagnóstico radiológico fue de masa renal compatible con tumor de Wilms (Fig. 1).

Con el diagnóstico de masa renal sólida derecha, compatible con neoplasia renal, se decidió realizar una PAAF con el objetivo de filiar la histología del tumor. El resultado anatomopatológico fue de oncocitoma renal.

Los hallazgos intraoperatorios fueron una masa renal derecha dependiente del polo inferior, que desplazaba cranealmente el riñón, siendo la exploración del riñón contralateral normal (Fig. 2). Presentaba un crecimiento expansivo pero no infiltraba cápsula renal, sistema pielo-calicial ni vasos renales. Se practicó una heminefrectomía inferior mediante control vascular del hilio renal e hipotermia local. Se tomaron biopsias intraoperatorias de los bordes de resección del tumor, que resultaron negativas. El parénquima residual, situado en polo superior, no mostraba alteraciones. No se encontraron adenopatías.

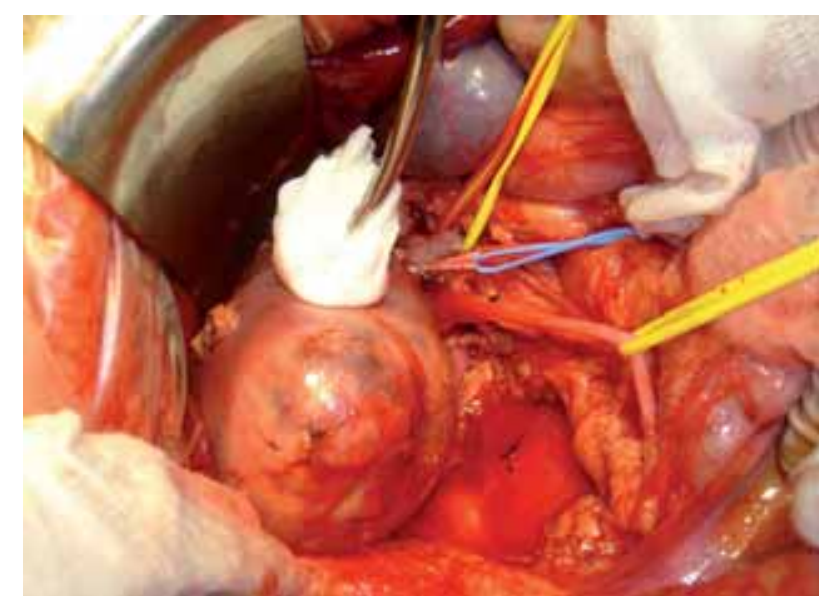

FIGURA 2. Tumoración infrarrenal derecha. Corte coronal.

El diagnóstico anatomopatológico fue de carcinoma renal de células cromófobas de 4-6 cm, bien delimitado y sin infiltración de cápsula ni grasa perirrenal. El estudio histoquímico reveló positividad a la tinción de hierro coloidal de Hale (Fig. 3).

El postoperatorio cursó sin incidencias, siendo dado de alta una semana después de la intervención. Se trata de un tumor de 4-6 cm, bien encapsulado y limitado a un polo renal, por lo que corresponde a un estadio I, no siendo necesario ningún otro tratamiento coadyuvante. Su seguimiento está siendo favorable, encontrándose libre de síntomas y de enfermedad.

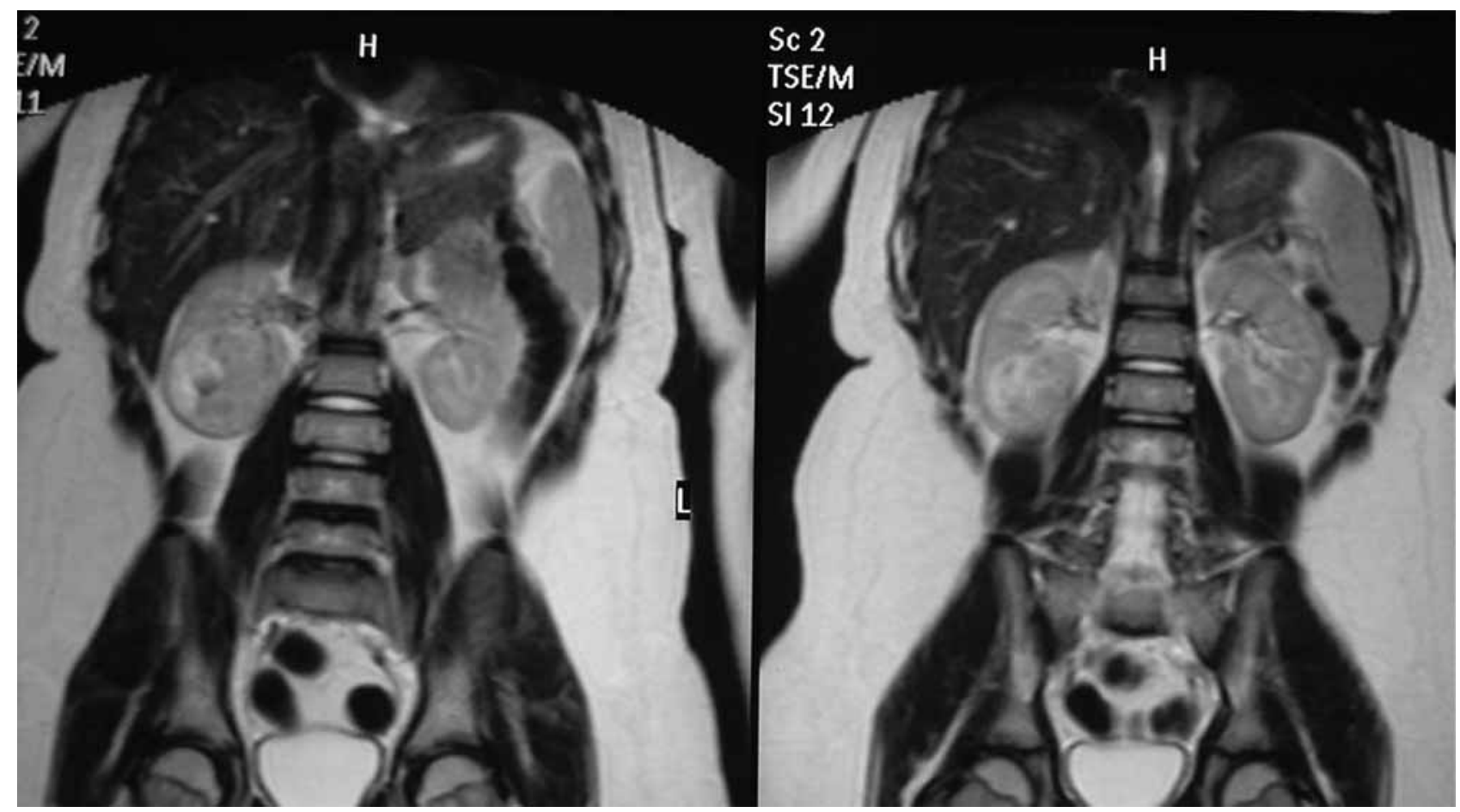

FIGURA 1. Tumor en polo renal inferior. 


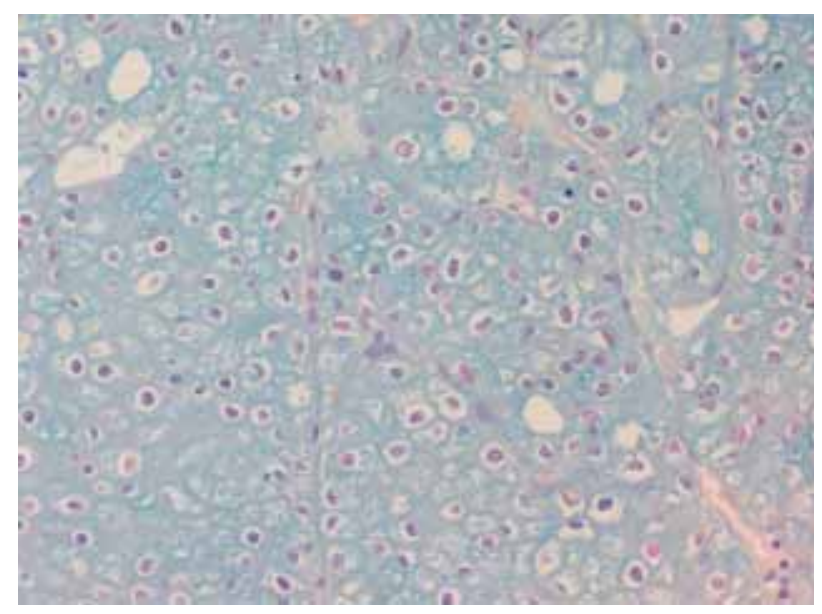

FIGURA 3. Tinción de hierro coloidal de Hale.

\section{DISCUSION}

El carcinoma renal de células cromófobas es una rara variante de carcinoma renal descrita por Thoenes en $1985^{1}$. Representa el 5\% de todas la neoplasias renales ${ }^{2,3}$, siendo excepcional su presentación en la edad pediátrica. Existen formas esporádicas y con menor frecuencia hereditarias.

Histológicamente, las células tienen citoplasmas grandes con membranas citoplasmáticas reforzadas y los núcleos binucleados e hipercromáticos. Estas características morfológicas pueden ser discriminatorias frente al oncocitoma renal. El oncocito es una célula epitelial eosinofílica cuyo citoplasma se caracteriza por su alto contenido en megamitocondrias, como lo demuestra la microscopía electrónica. El oncocitoma es una neoplasia epitelial compuesta de oncocitos agrupados en nidos celulares. La tinción de hierro coloidal de Hale es en el CRCC típicamente positiva difusa y citoplasmática .Esta característica histoquímica es de utilidad para diferenciar el CRCC del oncocitoma renal ${ }^{4,5}$.

El creciente número de exploraciones en pacientes con sintomas abdominales inespecíficos ha permitido el diagnóstico de los tumores renales con una mayor frecuencia y precocidad. La mayoría de los casos de CRCC se diagnostican en estadio T1-T2 y solo un 10\% se diagnostican en estadio T3 con invasión de cápsula y grasa perirrenal. Se han descrito algunos casos con metástasis pero generalmente asociados a formas hereditarias ${ }^{6}$.

La PAAF se ha mostrado útil en su diagnóstico, realizándose con bastante seguridad, guiada por ecografía o TAC; el riesgo de siembra tumoral en el trayecto de la punción es mínimo ${ }^{7}$. En nuestro caso, el resultado de la PAAF no fue concordante con el estudio histológico definitivo de la pieza de resección.

En el manejo quirúrgico de este tumor, si se trata de una masa renal sólida, que compromete todo o la mayor parte del órgano con riñón contralateral sano, el tratamiento de elección es la nefrectomía radical.

En tumores solitarios, confinados a un polo renal la nefrectomía parcial con biopsia intraoperatoria por congelación de los bordes de resección constituye el tratamiento de elección ${ }^{8}$. El tratamiento con quimioterapia sistémica no ha demostrado una clara efectividad en el CRCC. Tanto con las técnicas más antiguas de radioterapia como con las más modernas, tras la exéresis del tumor primario, no se ha demostrado un aumento de la supervivencia tras administrar radioterapia coadyuvante. Es un tumor de buen pronóstico, pues la supervivencia a los 5 años es del 80\%-90\%. La aparición de un fenotipo sarcomatoide se asocia con un crecimiento agresivo junto con el desarrollo de metástasis ganglionares y a distancia en pulmón, hígado y páncreas ${ }^{9,10}$.

\section{CONCLUSIONES}

El CRCC es una neoplasia rara en la infancia, aunque debe ser considerada en el diagnóstico diferencial de las masas renales en el niño. La realización cada vez más frecuente de ecografía para el estudio de diferentes patologías permite el diagnóstico del CRCC en estadios iniciales. Esto unido a su buen pronóstico permite la adopción de técnicas quirúrgicas que conserven la mayor parte del parénquima renal sano. El CRCC y el OR son neoplasias histogenéticamente relacionadas, compartiendo muchos hechos morfológicos y siendo, a veces, difícil el diagnóstico diferencial entre ambas.

\section{REFERENCIAS}

1. Thoenes W, Störkel S, Rumpelt HJ. Human Chromophobe cell renal carcinoma. Virch Arch B Cell pathol Inc Mol Pathol. 1985; 48(3):207-217.

2. Crotty TB, Farrow GM, Lieber MM. Chromophobe cell renal carcinoma: clinicopathological features of 50 cases. J.Urol. 1995; 154(3):964-967.

3. Peyromaure M, Misrai V, Throunn N, Vieillefond A, Zerbib M, Flam TA, et al. Cromophobe renal cell carcinoma. Analysis of 61 cases. Cancer. 2004;100(7):1406-1409. 
4. Lieber MM. Renal oncocytoma. Urology Clinic North Am. 1993; 20(2):355-359.

5. Dechet CB, Bostwick DG, Blute ML, Bryant SC, Zincke H. Renal oncocytoma: Multifocality, bilateralism, metachronous tumor development and coexistent renal cell carcinoma. J Urol.1999; 162(1):40-42

6. Renshaw AA, Richie JP. Subtyoes of renal carcinoma. Different onset and sites of

metastastic disease. Am J Clin Pathol. 1999;111(4):539-549.

7. Shenoy PD, Lakhkar BN, Ghosh MK, Patil UD. Cutaneous seeding of renal carcinoma by Chiba needle aspiration biopsy. Case report. Acta Radiol Diagn. 1991;32(1):50-52.

8. Chen TS, McNally M, Hulbert W, Di Sant'Agnese PA, Huang J. Renal oncocytosis presenting in childhood: A case report. Int $\mathrm{J}$ Surg Pathol. 2003;11(4):325-329.
9. Abrahams NA, Ayala AG, Czerniak B. Chromophobe renal cell carcinoma with sarcomatoid transformation. Ann Diagn Pathol. 2003;7(5):296-299.

10. Shannon BA, Cohen RJ. Rhabdoid differentiation of chromophobe renal cell Carcinoma. Pathology. 2003;35(3):228-230.

Correspondencia autor: Dr. I. Fernández Pineda

Servicio de Cirugía Pediátrica

Hospital Universitario Virgen del Rocío

Avda. Manuel Siurot, s/n - 41013 Sevilla

Tel.: 955012956

E-mail autor: israfdez@hotmail.com

Información artículo: Nota clinica

Trabajo recibido: enero 2007

Trabajo aceptado: marzo 2007 